\title{
Helicobacter pylori Urease: Potential Contributions to Alzheimer's Disease
}

\author{
Augusto F. Uberti 1,+, Natalia Callai-Silva ${ }^{2,+}$, Matheus V. C. Grahl ${ }^{3,+}$, Angela R. Piovesan ${ }^{4}$, Eduarda G. Nachtigall ${ }^{5}$, \\ Cristiane R. G. Furini ${ }^{6}$ and Célia R. Carlini ${ }^{7, *}$
}

1 Laboratory of Neurotoxins, Brain Institute of Rio Grande do Sul (BRAINS) and Graduate Program in Medicine and Health Sciences, Pontifícia Universidade Católica do Rio Grande do Sul (PUCRS), Porto Alegre, RS, CEP 90610-000, Brazil; afuberti@gmail.com

2 Laboratory of Neurotoxins, Brain Institute of Rio Grande do Sul (BRAINS) and Graduate Program in Medicine and Health Sciences, Pontifícia Universidade Católica do Rio Grande do Sul (PUCRS), Porto Alegre, RS, CEP 90610-000, Brazil; nati.callai@gmail.com

3 Laboratory of Neurotoxins, Brain Institute of Rio Grande do Sul (BRAINS) and Graduate Program in Medicine and Health Sciences, Pontifícia Universidade Católica do Rio Grande do Sul (PUCRS), Porto Alegre, RS, CEP 90610-000, Brazil; matheusgrahl@hotmail.com

4 Graduate Program in Cellular and Molecular Biology, Center of Biotechnology, Universidade Federal do Rio Grande do Sul (UFRGS), Porto Alegre, RS, CEP 91501-970, Brazil; angelapiovesan@gmail.com

5 Laboratory of Cognition and Memory Neurobiology, Brain Institute of Rio Grande do Sul (BRAINS) and Graduate Program in Biomedical Gerontology, Pontifical Catholic University of Rio Grande do Sul (PUCRS), Porto Alegre, RS, CEP 90610-000, Brazil; eduarda.godfried@gmail.com

6 Laboratory of Cognition and Memory Neurobiology, Brain Institute (BRAINS), Pontifical Catholic University of Rio Grande do Sul (PUCRS), Porto Alegre, RS, CEP 90610-000, Brazil; cristiane.furini@pucrs.br

7 Laboratory of Neurotoxins, Brain Institute (BRAINS) and School of Medicine, Pontifícia Universidade Católica do Rio Grande do Sul (PUCRS), Porto Alegre, RS, CEP 90610-000, Brazil; celia.carlini@pucrs.br

* Correspondence: celia.carlini@pucrs.br; Tel: +55 51-33205986

t these authors have contributed equally to this work

\begin{abstract}
Alzheimer's disease (AD) causes dementia and memory loss in the elderly. Deposits of beta-amyloid peptide and hyperphosphorylated tau protein are present in AD's brain. A filtrate of Helicobacter pylori's culture was previously found to induce hyperphosphorylation of tau in vivo, suggesting that bacterial exotoxins could permeate the blood brain barrier and directly induce tau's phosphorylation. H. pylori, which infects $\sim 60 \%$ of the world population and causes gastritis and gastric cancer, produces a pro-inflammatory urease (HPU). Here the neurotoxic potential of HPU was investigated in cultured cells and in rats. SH-SY5Y neuroblastoma cells exposed HPU (50-300 $\mathrm{nM}$ ) produced reactive oxygen species (ROS) and had an increased [Ca ${ }^{2+}{ }_{i}$. HPU-treated BV-2 microglial cells produced ROS, cytokines IL-1 $\beta$ and TNF- $\alpha$, overexpressed Iba1 and showed reduced viability, consistent with a neurotoxic effect of HPU. Rats received daily i.p. HPU ( $5 \mu \mathrm{g})$ for 7 days. Hyperphosphorylation of tau at Thr205, Ser199 and Ser396 sites was seen in hippocampal homogenates of treated rats, with no alterations in total tau or GSK-3 $\beta$ levels. HPU was not detected in the brain homogenates. Behavioral tests were performed to assess cognitive impairments. Our findings support previous data suggesting an association between infection by $H$. pylori and tauopathies such as AD, possibly mediated by its urease.
\end{abstract}

Keywords: Helicobacter pylori; urease; neuroinflammation; tau hyperphosphorylation; pro-inflammatory cytokines; object recognition test; elevated plus maze; SH-SY5Y neuroblastoma cells; BV-2 microglia

\section{Introduction}

Helicobacter pylori is known to infect approximately $60 \%$ of the world population, and in 2014 around 4.4 billion people were infected by this bacterium [1, 2]. In underdeveloped countries prevalence of $80 \%$ has been reported [3]. H. pylori infection is associated with several gastric pathologies, such as chronic gastritis, peptic and duodenal ulcers, gastric 
adenocarcinoma, and lymphoma of the mucosa-associated lymphoid tissue [4]. Epidemiological studies correlate $H$. pylori infection with several extra gastrointestinal pathologies $[5,6]$, such as ischemic heart disease [7], glaucoma [8], cerebrovascular diseases [9], autoimmune pancreatitis [10], and neurodegenerative diseases such as Alzheimer's disease (AD) [11, 12], mild cognitive impairment [13], and Parkinson's disease [14, 15]. Specifically in the case of $\mathrm{AD}$, the correlation is based on the high incidence of H. pylori in these patients $[12,16]$, as well as by the presence of anti-H pylori antibodies in their cerebrospinal fluid [11, 17]. In addition, Wang et al., in 2015 [18], reported that a H. pylori culture filtrate, obtained without lysis of the bacterium, induced hyperphosphorylation of tau in the hippocampi of rats, both in vivo and in vitro, marked by increased phosphorylation in three specific tau sites, Thr205, Thr231 and Ser404. The H. pylori filtrate also caused activation of the GSK-3 $\beta$ kinase in mouse neuroblastoma cells (N2a). However, this filtrate did not induce a significant cerebral inflammatory response. Based on these data, the authors suggested that $H$. pylori-induced tauopathy could be due to exotoxin(s) produced by the bacterium, capable of penetrating the blood-brain barrier and directly inducing tau phosphorylation. As the authors did not characterize the filtrate, or attempted to isolate any of its components, the existence and/or identity of these exotoxin(s) remains unknown.

H. pylori's urease (HPU) is a cytoplasmic protein that can also be found on the surface of the bacteria, presumably adsorbed by viable cells as a result of the lysis of bacterial subpopulations sensitive to stomach acid [19]. HPU is the most abundant protein produced by H. pylori, allowing the bacteria to survive in the gastric mucosa due to the enzymatically generated ammonia that forms a neutral microclimate in the extremely acidic environment of the stomach [20]. Besides regulating the intracellular $\mathrm{pH}$ by releasing ammonia, HPU also alkalinizes the extracellular $\mathrm{pH}$, from the diffusion of ammonia to the periplasm and the environment around the bacteria [21]. Urease-negative $H$. pylori mutants are unable to colonize the stomach of gnotobiotic piglets and nude mice [22, 23]. In addition, HPU is widely used for diagnosis of $H$. pylori infection [24, 25]. Previous studies by our group have shown that different ureases, including HPU, display biological properties independent of their enzymatic action, which can potentially contribute to the pathogenesis of infections caused by the urease-producing bacteria (for review see [26, 27]. In platelets, HPU induces secretion and degranulation of ADP-containing granules, which leads to platelet aggregation, responses accompanied by the production of eicosanoids derived from the 12-lipoxygenase pathway [28]. Platelet activation, mediated by HPU, turns these cells into a pro-inflammatory phenotype [29], reinforcing the importance of neutrophil and platelet-mediated inflammation in the inflammatory process caused by $H$. pylori $[30,31]$. HPU also activates other cell types, such as monocytes, neutrophils, endothelial cells, and gastric epithelial cells. Human neutrophils activated in vitro by HPU are protected from apoptosis and produce reactive oxygen species (ROS), and in vivo, HPU induces neutrophil migration in the mouse paw edema model [30]. Our group has shown that HPU participates in pro-angiogenic processes, suggesting that the urease may be involved in the development of gastric carcinoma [32]. Moreover, HPU weakens cell junctions [33], altering the integrity of the endothelial cell barrier and increasing paracellular permeability [34]._HPU also promoted the differentiation of human endothelial cells. This mechanism is related to the production of ROS, which together with the weakening of the endothelial barrier, supposedly contributes to the progression of $H$. pylori infection to gastric carcinogenesis [34]).

Neuroinflammation has emerged as an important causal mechanism of dementia, especially in cases of Alzheimer's disease (AD), which is the most prevalent type of dementia. A high degree of glial cell activation was observed in early stages of the disease, suggesting a vulnerability of the CNS to inflammation in AD. As the disease progresses, an extensive stunted brain tissue is triggered [35]. In humans, a study using positron emission tomography showed that very high peripheral levels of C-reactive protein, an easily measurable inflammation marker, are associated with increased microglial activation [36]), thus confirming that peripheral inflammation can promote changes in the brain's immune system. Therefore, chronic peripheral inflammation, such as that caused by 
chronic $H$. pylori infection, can contribute to the development of brain inflammation and neurodegenerative diseases [37]. Considering the epidemiological association between infection by H. pylori and Alzheimer's Disease [1], the data showing that the filtrate of the bacteria's culture induces hyperphosphorylation of Tau [18] and considering that HPU is the most abundant virulence factor of the bacteria, it is important to investigate whether it could have a relevant role in the development of tauopathies. Considering its proinflammatory activity, its presence in microvesicles produced by the bacterium [38], or as a free protein released into the bloodstream from inflamed gastric tissue, HPU could potentially contribute to disrupt the blood-brain barrier and thus reach the central nervous system, where it could exert neurotoxic effects. In this work we aimed to evaluate the neurotoxicity of HPU on CNS cells in in vitro models. We also evaluated the in vivo effects of HPU on hippocampal homogenates, seeking to understand the signaling triggered by the urease. Behavioral experiments were performed to investigate a possible role of HPU in early AD symptoms.

\section{Results}

\subsection{In Vitro Effects of HPU in CNS Derived Cell Lines}

\subsubsection{Toxicity to Human Neuroblastoma Cells}

Undifferentiated human neuroblastoma cells SH-SY5Y were pre-loaded with the reactive oxygen species (ROS) fluorogenic probe CM-DFFDA (2 mM) and then treated with different concentrations of HPU (50, 100 and $300 \mathrm{nM})$. A tendency to an increased production in HPU-treated cells was seen either after 6 or $24 \mathrm{~h}$ of exposition to the urease. On the other hand, SH-SY5Y cells showed significant increased levels of intracellular $\mathrm{Ca}^{2+}$ upon 24 h of incubation with 300 nM HPU compared to control cells (Figure 1).

A

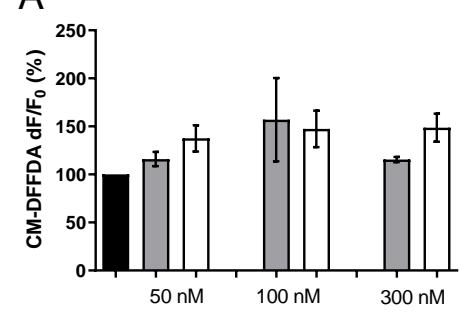

B

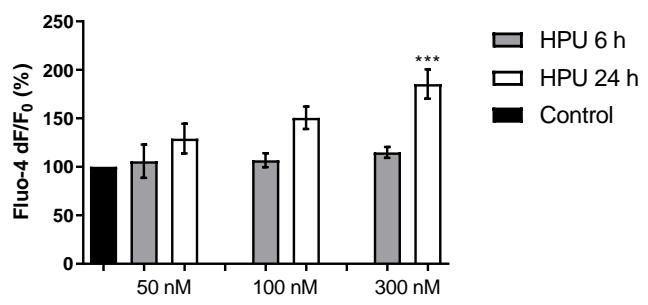

Figure 1. Toxicity to SH-SY5Y cells. (A). Undifferentiated SH-SY5Y cells were incubated with CMDFFDA ( $2 \mathrm{mM}$ ) probe for $30 \mathrm{~min}, 37^{\circ} \mathrm{C}$, in the dark. Cells were treated for 6 hours (gray columns) and 24 hours (white columns) with $20 \mathrm{mM} \mathrm{NaPB}$ (control) or 50, 100 or $300 \mathrm{nM}$ HPU. Fluorescence was measured at $\lambda_{\text {ex }} 495 \mathrm{~nm} / \lambda_{\text {em }} 527 \mathrm{~nm}$. The results are expressed as $\%$ of the control \pm SEM and compared by one-way ANOVA followed by the Tukey test. (B). For calcium measurement, undifferentiated SH-SY5Y cells were incubated with Fluo-4AM probe $(5 \mu \mathrm{M}$, in $20 \mathrm{mM} \mathrm{NaPB})$ for $45 \mathrm{~min}$, $37^{\circ} \mathrm{C}$, in the dark. The treatment with 50,100 or $300 \mathrm{nM} \mathrm{HPU}$ lasted for 6 (gray columns) or 24 hours (white columns). Controls with $20 \mathrm{mM} \mathrm{NaPB}$ ( 6 and 24 hours) were considered $100 \%$. Fluorescence was measured at $\lambda_{\mathrm{ex}} 488 \mathrm{~nm} / \lambda_{\mathrm{em}} 530 \mathrm{~nm}$. The results were expressed as $\%$ of the control $\pm \mathrm{SEM}$ and compared by one-way ANOVA followed by the Tukey test. ${ }^{* *} \mathrm{p}<0.001$ vs. control.

\subsubsection{Activation of BV-2 Microglial Cells}

Microglia are the main cell of the brain innate immune system, displaying macrophage-like characteristics. Microglial activation into an M1 phenotype leads to an increase in proinflammatory cytokines, which contributes to neurotoxicity [39]. Our data showed that HPU-activated BV-2 cells produced ROS at the highest tested dose, and showed a marked reduction in viability after 24 hours of treatment (Figure 2). HPU also induced IL$1 \beta$ and TNF- $\alpha$ production and Iba1 expression in BV-2 cells, indicating a pro-inflammatory phenotype (Figure 3). 


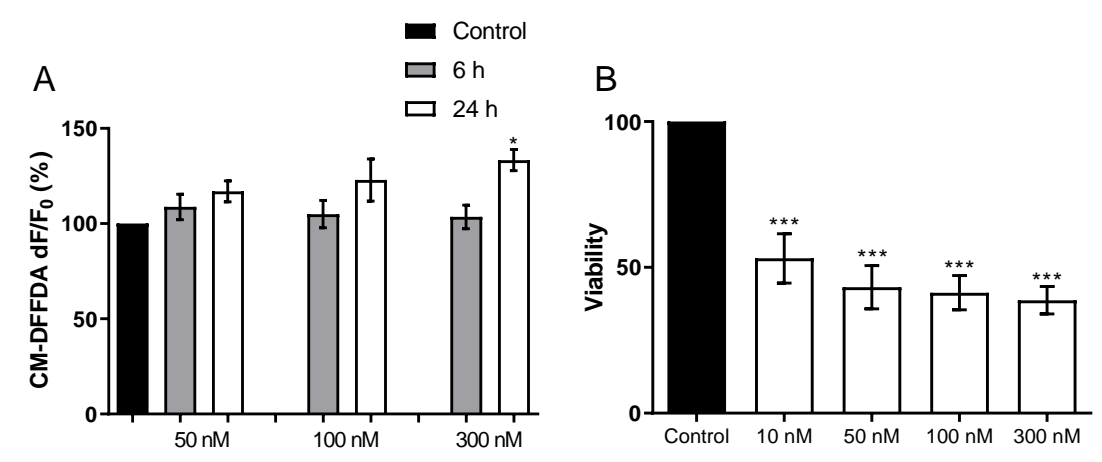

Figure 2. Toxicity of HPU to BV-2 cells (A). For ROS detection, BV-2 cells were incubated CMDFFDA $2 \mathrm{mM}$ probe for $30 \mathrm{~min}, 37^{\circ} \mathrm{C}$, in the dark. After washing, BV-2 cells were incubated with $20 \mathrm{mM} \mathrm{NaPB}$ (control), or 50, 100 or $300 \mathrm{nM} \mathrm{HPU}$ for 6 hours (gray columns) or 24 hours (white columns). Fluorescence was measured at $\lambda_{\text {ex }} 495 \mathrm{~nm} / \lambda_{\mathrm{em}} 527 \mathrm{~nm}$. The results were expressed as $\%$ of the control \pm SEM and compared by one-way ANOVA followed by the Tukey test. ${ }^{*} \mathrm{p}<0.05$ vs controls. (B). BV-2 viability was analyzed by the MTT test after $24 \mathrm{~h}$ of exposure to HPU. The cultures' supernatants were removed after the treatments and cells were incubated with MTT (5 $\mathrm{mg} / \mathrm{mL}$ ) for $4 \mathrm{~h}$ at $37^{\circ} \mathrm{C}$, then suspended in $100 \mu \mathrm{L}$ DMSO. Absorbances were read at $570 \mathrm{~nm}$. Mean \pm SEM. ${ }^{* * *} \mathrm{p}<0.001$ vs. control.

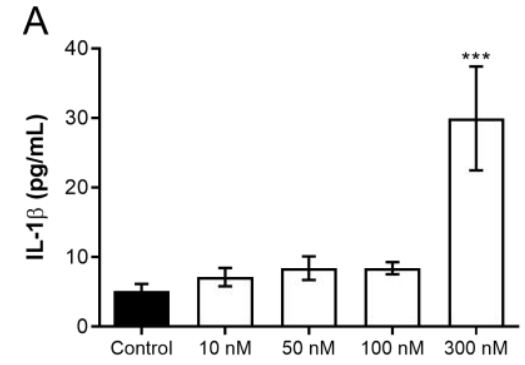

B

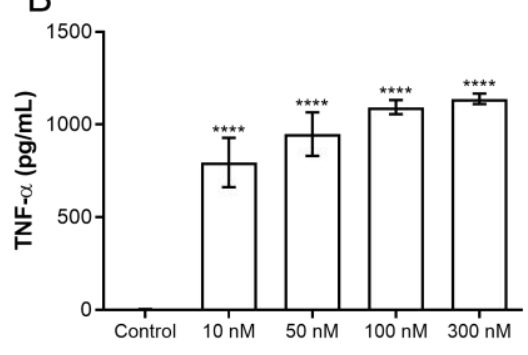

C

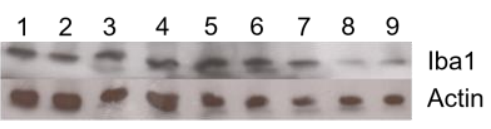

D

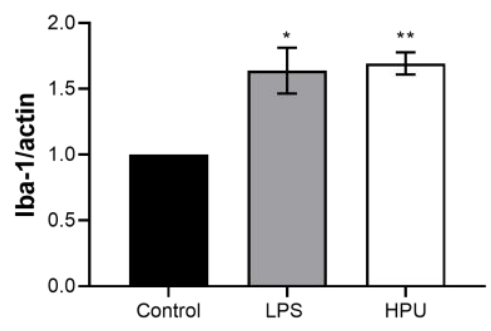

Figure 3. Microglial BV-2 activation by HPU. For detection of cytokine expression, BV-2 cells were incubated for $6 \mathrm{~h}$ with HPU, and cultures' supernatants were collected for detection of IL-1 $\beta$ (panel A) and TNF- $\alpha$ (panel B) by ELISA. The data (mean \pm SEM) were analyzed by one-way parametric ANOVA with a Dunnett post-test. ${ }^{* * *} \mathrm{P}<0.001{ }^{* * * *} \mathrm{P}<0.0001$ vs. control. Panels $\mathrm{C}$ and $\mathrm{D}$ : Iba1 levels in brain homogenates of HPU-treated rats were analyzed by Western blots (C), lanes 1-3, HPUtreated; lanes 4-6, LPS-treated (positive control); 7-9, buffer-treated (negative control), and quantified by densitometry (D). The data (mean \pm SEM) were analyzed by one-way ANOVA followed by Bonferroni post hoc test. ${ }^{*} \mathrm{p}<0.05,{ }^{* *} \mathrm{p}<0.01$ vs controls.

\subsection{Evaluation of Total and Phosphorylated Hippocampal Tau Levels in Rats Treated with HPU}

Considering the data reported by Wang et al. 2015 [18] on tau protein phosphorylation in rats treated i.p. with H. pylori filtrates, in this work we sought to investigate if HPU could play a role in this process. In order to verify the effects of intraperitoneally administered HPU on the total content of tau protein, Western blot assays using monoclonal anti-Tau5 antibody were performed on rat hippocampal homogenates after 7 days of treatment (Figure 4A). No significant difference of total tau levels between the control and 
treated groups $(1.252 \pm 0.6518 ; 1.019 \pm 0.3188$, respectively) was seen. This result corroborates that of Wang et al., 2015 [18], who described no changes in the total tau levels in rats treated with $H$. pylori filtrate.

On the other hand, in vivo treatment of rats with HPU promoted tau phosphorylation on Thr205, Ser396 and Ser199 sites (Figure 4B-D). A significant increase in phosphorylation levels in Thr205 of at least one of the three isoforms of Tau was found in animals treated intraperitoneally with HPU for 7 days $(1.233 \pm 0.0847 ; p=0.0249)$. The phosphorylation of tau at Ser396 was reported to be one of the first phosphorylation events in early stages of AD development [40], detected even before conformational changes in the protein occur. Here an increase in tau Ser396 phosphorylation was seen in animals treated for 1 week with HPU $(1.474 \pm 0.1514 ; \mathrm{p}=0.014)$ compared to the control group. Tau's Ser199 phosphorylation site is also related to the early stages of AD development [41]. In this work, we found that the 7 days treatment with HPU promoted a significant increase $(\mathrm{p}=$ $0.0093)$ of tau phosphorylation at the S199 site $(1.484 \pm 0.1421)$ when compared to the control group $(0.9823 \pm 0.1921)$ (Figure $4 \mathrm{D})$. All data were normalized against the endogenous actin content.

A
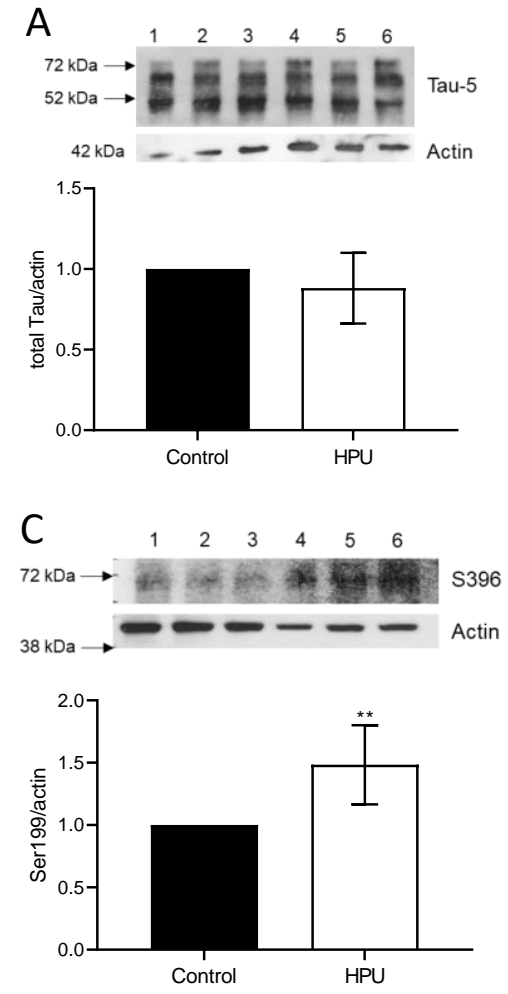

B
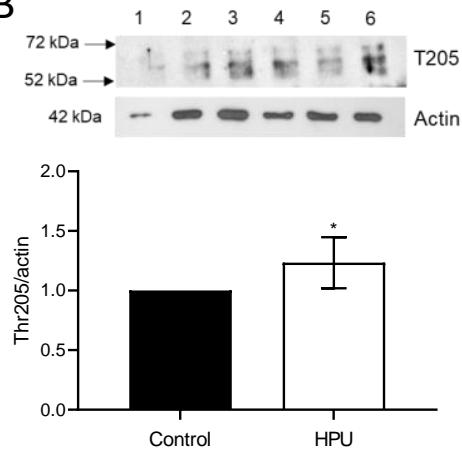

D
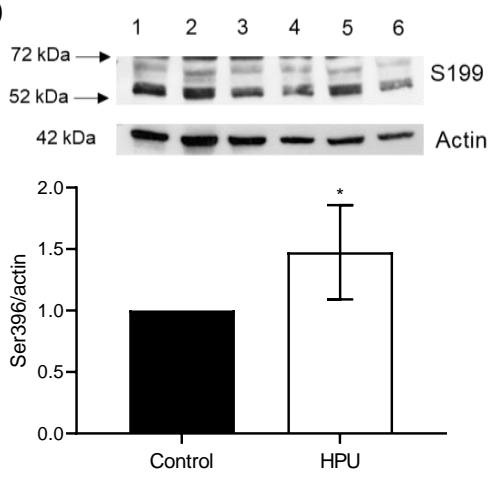

Figure 4. Quantification of total and phosphorylated tau protein in hippocampal homogenates of HPU-treated rats. Male 30 days old Wistar rats received i.p. injections of HPU for 7 days (5 $\mu \mathrm{g} / \mathrm{rat} /$ day), and the same volume of sterile saline was administered to the control group. Western blot assays were performed with hippocampal homogenates of animals from three independent experiments (G1, G2, G3), each composed of a treated group and a control group $(\mathrm{N}=4)$. Controls (lanes 1, 3 and 5) and HPU-treated (lanes 2, 4 and 6) homogenates were analyzed for total (panel A) and phosphorylated tau at sites Thr205 (panel B), Ser199 (panel C) and Ser396 (panel D). The levels of tau protein were normalized by that of actin. The figure depicts representative blots and their densitometric analysis. Data are expressed as mean \pm SD and analyzed by one-way ANOVA followed by Bonferroni post hoc test. ${ }^{*} \mathrm{p}<0.05,{ }^{* *} \mathrm{p}<0.01$ vs controls.

\subsection{Evaluation of GSK-3 $\beta$ Levels.}

GSK-3 $\beta$ is an isoform of the GSK3 kinase abundantly found in the nervous system $[42,43]$ and it phosphorylates tau sites usually related to the development of AD [44, 45]. 
We investigated the levels of GSK-3 $\beta$ and no significant difference was found between the control groups and HPU-treated rats $(p=0,2845)$ (Figure 5).

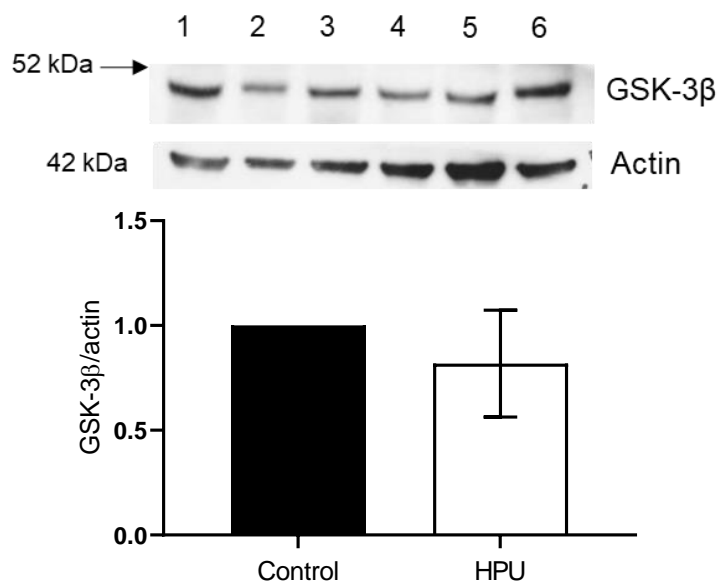

Figure 5. Quantification of GSK-3 $\beta$ kinase levels. Male Wistar rats received i.p. injections of HPU for 7 days $(5 \mu \mathrm{g} / \mathrm{rat} / \mathrm{day})$, and the same volume of sterile saline was administered to the control group. Western blotting assays were performed with hippocampal homogenates of animals from three independent experiments (G1, G2, G3), each composed of a treated group and a control group $(\mathrm{N}=4)$. Controls (lanes 1, 3 and 5) and HPU-treated (lanes 2, 4 and 6) homogenates were analyzed for GSK-3 $\beta$ and actin protein levels. The figure shows a representative blot and its densitometric analysis. Data are expressed as mean \pm SD and analyzed by one-way ANOVA followed by Bonferroni post hoc test.

\subsection{Blood-Brain Barrier Permeability Assessment of Rats Treated with HPU}

To assess the permeability of the blood-brain barrier (BBB) to HPU, brain homogenates of the animals were analyzed by Western blot, using the primary antibodies antiure $\beta$ and anti-ure $\alpha$, specific for detection of the urease's B chain and A chain, respectively. As shown in Figure 6, the amount of HPU (if present) in the brain tissue of the treated rats are below detection level $(0.116 \mu \mathrm{g} / \mathrm{mL})$. This result suggests that there was no damage to the integrity of the BBB under the tested conditions.

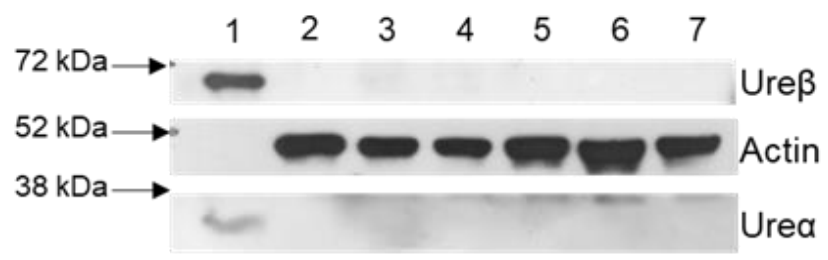

Figure 6. Blood-brain barrier integrity of rats treated with HPU. Male Wistar rats received i.p. injections of HPU for 7 days ( $5 \mu \mathrm{g} / \mathrm{rat} /$ day), and the same volume of sterile saline was administered to the control groups. Hippocampal homogenates from three independent experiments (G1, G2, G3), each composed of a treated group and a control group $(\mathrm{N}=4)$, were analyzed by Western blot assays using antibodies against HPU subunit B (ure $\beta$ ) and subunit A (ure $\alpha)$ (62 kDa and $30 \mathrm{kDa}$, respectively). The figure illustrates a typical blot, with controls in lanes 2, 4 and 6, and HPU-treated groups shown in lanes 3, 5 and 7. Purified HPU protein $(25 \mu \mathrm{g})$ is seen in lane 1.

\subsection{Behavioral Tests}

To investigate a possible role of HPU in early AD symptoms of $H$. pylori-infected patients, we evaluated memory and anxiety-like behavior in young adult Wistar rats. The object recognition test is used to test learning and memory, as rodents are innately curious and tend to explore novelty [46]. Rats without memory impairment would spend more time exploring the novel object in the test session. In our 7-days experiment, no difference was observed between groups, despite the biochemical features of AD being observed in 
the brains of HPU-treated rats, such as neuroinflammation and tau phosphorylation (Figure 7).

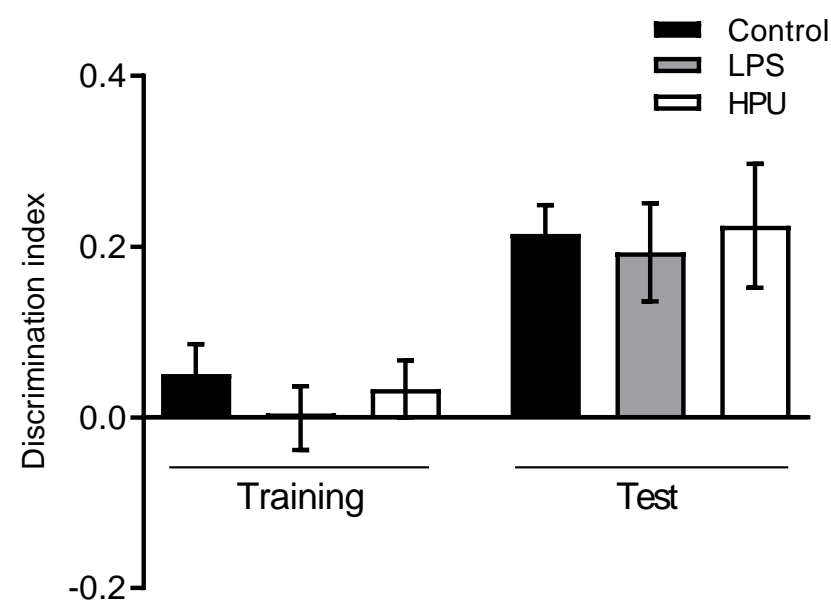

Figure 7. Effect of HPU on memory consolidation. Male Wistar rats received i.p. injections of HPU ( $5 \mu \mathrm{g} / \mathrm{rat} /$ day), LPS ( $1 \mathrm{mg} / \mathrm{kg} / \mathrm{rat} /$ day, positive control) or saline (negative control) for 7 days. Discrimination indexes in the test phase were analyzed by one-way ANOVA followed by Bonferroni's multiple comparison test. Data expressed as median \pm SEM. $n=10$ rats/group.

The elevated plus-maze test evaluates anxiety-like behavior, as rodents are naturally averted to open and elevated spaces [47]. In the 7-days experiment, all rats behaved similarly, with no signs of anxiety or discomfort, and no difference was observed among the groups (Figure 8).
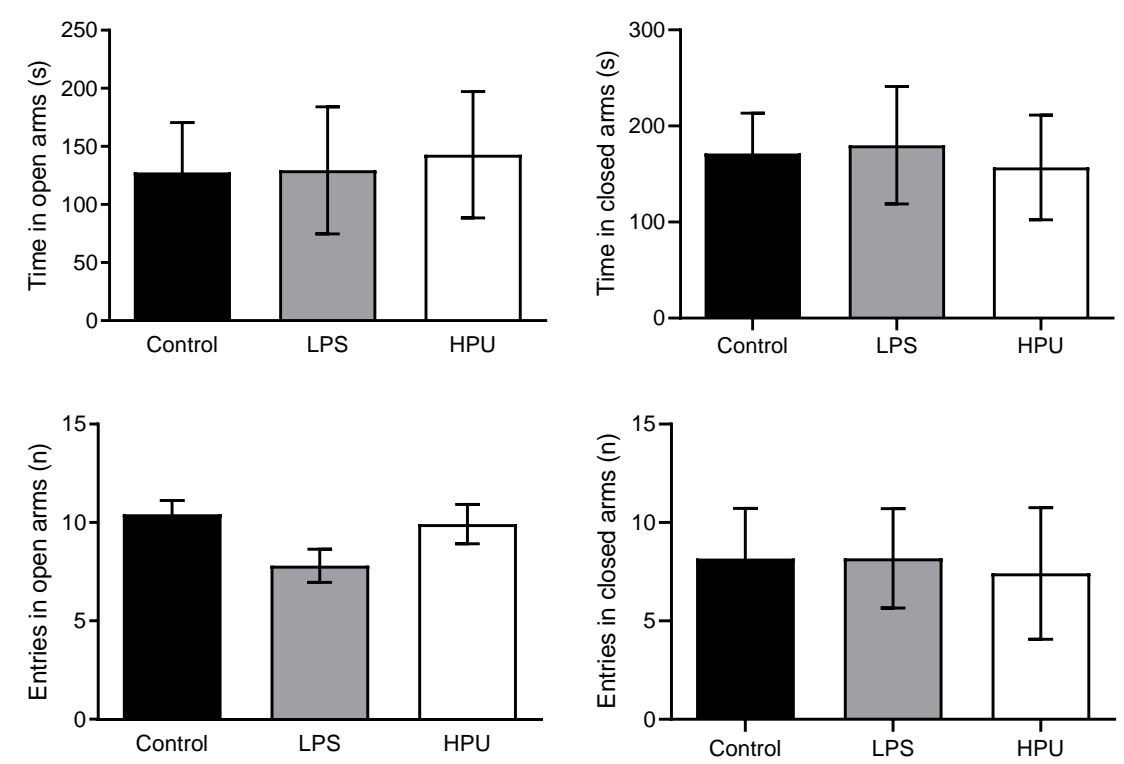

Figure 8. Elevated Plus-Maze performance of HPU-treated rats. Male Wistar rats received i.p. injections of HPU ( $5 \mu \mathrm{g} / \mathrm{rat} / \mathrm{day})$, LPS ( $1 \mathrm{mg} / \mathrm{kg} / \mathrm{rat} / \mathrm{day}$, positive control) or saline (negative control) for 7 days. Entries to open and closed arms of the elevated maze and time spent in each arm were measured. Data were analyzed by one-way ANOVA followed by Bonferroni's multiple comparison test. Data expressed as median \pm SEM. $n=10$ rats/group.

\section{Discussion}


In 2009, Lo et al [48] reported in vitro toxicity in gastric epithelial, neuroblastoma and microglia cell lines after treatment with a supernatant of $H$. pylori culture medium, either directly or in co-culture. In addition, it was observed that death of SH-SY5Y cells depended on the activation of BV-2 cells, suggesting that microglia play an important role in H. pylori-induced neurotoxicity. Considering that HPU represents 10 to $15 \%$ of the protein content of $H$. pylori $[19,27]$, this urease is certainly present in the culture's supernatant, which these authors called " $H$. pylori-conditioned medium".

Physiological concentrations of ROS in epithelial cells can act as signals for several biological responses, including regulation of adhesion molecules and chemokines, formation of intercellular spaces and leukocyte migration [34, 49,50]. Our group has previously demonstrated that HPU induces a significant increase in ROS production in neutrophils [30] and HMEC-1 epithelial cells [34]. In this work, we observed a tendency to elevated ROS levels in HPU-treated SH-SY5Y and a significant increase of ROS production in BV-2 cells after 24 hours of treatment. The same dose range of HPU which produced other effects described here was used in the ROS experiment. It is possible that ROS production follows a distinct kinetics in SH-SY5Y cells and production could be greater in other experimental times. Moreover, the production of ROS could be extracellular and thus not detected by the CM-DFFDA probe.

The calcium ion $\left(\mathrm{Ca}^{2+}\right)$ is a second intracellular messenger that regulates different cellular functions, such as membrane excitability, exocytosis, synaptic activity and gene expression [51]. $\mathrm{Ca}^{2+}$ in neurons is the coupling factor between excitation and propagation of electrochemical signals, intervening in many neuronal physiological responses to chemical and electrical stimuli. Changes in the levels of intracellular $\mathrm{Ca}^{2+}$ can also cause neuron death, and its homeostasis is carefully controlled [52]. In neurons, the concentration of $\mathrm{Ca}^{2+}$ is maintained at very low levels, and an exacerbated increase in cytosolic [ $\mathrm{Ca}^{2+}$ ] can result in neuronal death by necrosis, while a prolonged decrease in cytosolic $\left[\mathrm{Ca}^{2+}\right.$ ] leads to the induction of cell death by apoptosis $[53,54]$. In SH-SY5Y cells, which have a neuronal origin, HPU promoted cytosolic [ $\mathrm{Ca}^{2+}$ increase in a dose and time-dependent manner. Increase in cytosolic $\left[\mathrm{Ca}^{2+}\right]$ is known to cause apoptosis and/or autophagy [5557]. Since no $\mathrm{Ca}^{2+}$ was added to the cell culture medium, the observed increase in $\left[\mathrm{Ca}^{2+}\right.$ ] indicates mobilization of intracellular calcium pools. Other signs of neurotoxicity of HPU to SH-SY5Y cells await to be evaluated including measurements of pro-inflammatory cytokines. Also, in this experiment, shorter incubation times of cells with HPU should be tested.

BV-2 cell line exhibits phenotype and functional properties of activated microglia [58] - an essential condition for the immune response in the CNS that the activated microglia are associated with. As discussed in the previous paragraphs, both an increase and a decrease in the concentration of cytosolic $\left[\mathrm{Ca}^{2+}\right]$ can be harmful and consequently neurotoxic to cells. Interestingly, in microglial BV-2 cells, HPU did not promote an increase in the levels of intracellular $\left[\mathrm{Ca}^{2+}\right]$ (data not shown). The reason for the contrasting responses of these two cell types to HPU remains unknown. It is worth mentioning that this same contrasting responses in the levels of $\left[\mathrm{Ca}^{2+}\right]$ were seen for SH-SY5Y and BV-2 cells treated with Proteus mirabilis urease, another bacterial urease with neurotoxic properties [59].

Overexpression of proinflammatory cytokine IL-1 $\beta$ produced by microglia and astrocytes close to $\mathrm{A} \beta$ plaques are recurrent in the brain affected by $\mathrm{DA}$, as well as in animal models of DA $[60,61]$. IL- $1 \beta$ production is dependent on MAPK activation and NF- $\kappa B$ signaling cascade, and studies report that overexpressed IL- $1 \beta$ increases tau phosphorylation and NFT formation, due to GSK-3 $\beta$ activation [62]. It has been shown that HPU, especially the B subunit, activates the NLRP3 inflammasome, in a TLR2 dependent manner, which is the first step for IL-1 $\beta$ synthesis $[18,63]$. Here, we report an increase in the production of IL-1 $\beta$ by BV-2 cells primed with HPU (300 nM). Brain homogenates from the 7-days experiment showed an increase in Iba1 expression, indicating an activation status. BV-2 cells also had a significant reduction in viability when treated with HPU. In the $300 \mathrm{nM}$ dose of HPU, viability was reduced by more than 60\% (Figure 2). LPS was used as a positive control as it is known to activate BV-2 cells, turning these cells into an 
inflammatory phenotype, inducing the synthesis of proinflammatory markers and reducing BV-2 viability [64].

The neurotoxicity of purified HPU administered to rats intraperitoneally was first described by Baik and colleagues in 2005 [65], who observed hypothermia, convulsion and death of the animals. It should be noted that these same effects occur in rats and mice injected with CNTX, a highly neurotoxic urease isolated from the Canavalia ensiformis plant, and these events are independent of the protein's enzymatic activity [66, 67]. However, these symptoms of HPU's neurotoxicity do not allow establishing, from epidemiological data, that there is a correlation between $H$. pylori infection with AD tauopathy. Mondragón-Rodríguez et al., 2014 [40] reported that phosphorylation in tau's carboxy terminal region could be related to early AD-related tau phosphorylation events, occurring before the classic appearance of NFT, one of the hallmarks of the disease. Among tau's phosphorylation sites, some are located in the proline-rich region (P-region) (residues 172251) and in the carboxy terminal region (C-region) (residues 368-441) [45]. In this work we found increased phosphorylation of tau in HPU-treated rats in two sites located in the $\mathrm{P}$ region (Thr205 and Ser199) and one site in the C region (Ser396). Our findings corroborate previous epidemiological and animal model studies, which describe the correlation between $H$. pylori infection and AD [1], and point to a potential role of HPU in this correlation.

Although we could not detect HPU in the brain homogenates of treated rats (Figure 6), it is still premature to reach the conclusion that HPU administered intraperitoneally could not cross the BBB. Even if there was an opening of the BBB, the enormous size of HPU molecule, with a molecular mass of $1.1 \mathrm{MDa}$ would pose difficulties to its entrance into the CNS. In the experimental conditions used, the animals received a total of $35 \mu \mathrm{g}$ of HPU over 7 days. Assuming that the total amount of HPU administered was evenly distributed in the body of a $150 \mathrm{~g}$ rat, of which $70 \%$ is water, the HPU "concentration" in the animal would be approximately $0.33 \mu \mathrm{g} / \mathrm{mL}$. Under the conditions of our experiment, the antibodies against either subunit of HPU would still be able to detect the presence of the protein in the brain homogenates in concentrations below $0.116 \mu \mathrm{g} / \mathrm{mL}$ of urease. A possible explanation for the negative result shown in Figure 6 is that the Western blot test was not sensitive enough to detect very small amounts of HPU if present in the samples.

Extracellular vesicles play an important role in the activity of the CNS, since they act not only in the signal transmission between neurons, as well as in the communication between the CNS and all peripheral systems. As particles on the nanometer scale, they can cross the blood-brain barrier [68]. Microvesicles produced by H. pylori carrying CagA were immunolocated in proximity to occlusive junctions of epithelial cells, from where they are internalized [69]. The presence of HPU in H. pylori microvesicles was characterized by mass spectrometry [38]. Thus, in the context of $H$. pylori infection, the possibility of microvesicles carrying HPU through the BBB should be considered [38, 69]. In the article by Baik et al. in 2005 [65], a 20-fold increase in serum ammonia levels was measured in animals treated intraperitoneally with $H$. pylori filtrate, reflecting the enzymatic action of HPU. It is known that hyperammonemia is a condition that can lead to changes in the blood-brain barrier in humans. Thus the additive effect of hyperammonemia consequent to HPU's enzymatic activity and its effect directly on endothelial cells, increasing the paracellular permeability [34], would eventually allow the entry of circulating HPU into the CNS [70-72]. Finally, it is necessary to consider that a low, but persistent, increase in serum ammonia levels during $H$. pylori infection, that can persist asymptomatic for decades, could be the factor that triggers the hyperphosphorylation of tau as observed here. There are metabolomic studies that identified hyperammonemia associated with animal models of Alzheimer's Disease [70, 73]. In view of these considerations, further studies are still needed to reach a conclusion on the possibility of HPU crossing the BBB, whether of the free protein in the circulation and/or carried by microvesicles produced by H. pylori. Urease-activated signaling routes that may interfere with brain tau phosphorylation should be further investigated. Previous data from our group showed that HPU can modulate signaling pathways involving lipoxygenase-derived eicosanoids and to alter intracellular 
calcium levels in rabbit platelets, human neutrophils and human endothelial cells [28, 34, 74]. Eicosanoids are known to be involved in neuroinflammation [75, 76], a condition that also exists in DA [77, 78].

It is well known that biochemical hallmarks precede the cognitive decline observed in AD patients [79]. This may explain why we did not observe any behavioral changes in the conditions tested. Both, neither memory impairment or anxiety-like behavior, were altered in HPU-treated rats. Surprisingly, no alterations were seen also in LPS-treated rats, although the literature reports of LPS-induced memory loss under experimental conditions similar to ours [80,81]. However, other studies did not find effect of LPS on behavioral analyses, including different memory tests and anxiety-like behavior $[82,83]$. The earliest pathophysiological biomarker of $\mathrm{AD}$ is the accumulation of $\mathrm{A} \beta$ peptide [79]. Wang and co-workers reported in 2014 that the 7 days treatment of 30 days-old rats with the $H$. pylori filtrate promoted impairment spatial learning and memory loss, accompanied by accumulation of the A $\beta$ peptide in the animals' brain [84]. Besides HPU, other bacterial exotoxin(s) in the filtrate may act synergistically with the urease in promoting neuroinflammation and cognitive impairment. H. pylori infection lasts for decades, inducing a chronic inflammatory response. Here the 7 days of treatment with HPU was chosen for comparison with the data presented by Wang et al, 2015 [18], with the H. pylori's filtrate. This condition mimics an infection in young rats (30 days-old), however although biochemical markers of neuroinflammation and hyperphosphorylated tau were present, the 7 days treatment was clearly not enough to produce behavioral alterations. Thus we are now carrying out experiments to assess behavioral alterations and neuroinflammatory biomarkers after much longer schedules of HPU treatments.

Altogether, the data presented here is an indication that H. pylori's urease is an important virulence factor also for the development of extra gastric diseases, including Alzheimer's Disease. HPU's pro-inflammatory activity and activation of the immune system causing neuroinflammation and tau phosphorylation should not be overlooked as significant contributors for the progression of neurodegenerative diseases.

\section{Materials and Methods}

\subsection{Cell Culture}

Cell lines BV-2 (BCRJ (Banco de Células do Rio de Janeiro, Rio de Janeiro, Brazil) kindly donated by Dr. Silvia Farsky, USP, Brazil) and SH-SY5Y (ATCC® CRL-2266 ${ }^{\mathrm{TM}}$ ) kindly donated by Dr. Fabio Klamt, UFRGS, Brazil) were maintained in RPMI and DMEM/F12 medium (Invitrogen, Thermo Fisher, MA, USA), respectively, supplemented with 10\% fetal bovine serum (FBS, HyClone ${ }^{\mathrm{TM}}$, GE Healthcare Life 91 Sciences, UT, USA), $1 \%$ Pen/Strep (Invitrogen) at $37^{\circ} \mathrm{C}$ under $5 \% \mathrm{CO}_{2}$ humidified atmosphere.

\subsection{HPU Purification}

Recombinant Helicobacter pylori urease (HPU) was produced by heterologous expression in Escherichia coli BL21 (DE3)-RIL transformed with a PGEM-T-easy (Promega) plasmid carrying the whole urease operon (kindly provided by Dr. Barbara Zambelli, Universitá di Bologna, Italy). HPU was purified from bacterial extracts according to OliveraSevero et al. 2017[32]. Protein purity was verified by SDS-PAGE.

\subsection{Protein Determination}

The protein content of samples was determined by absorbance at $280 \mathrm{~nm}$, or by the Coomassie dye binding method.

\subsection{Urease Activity.}

The urea hydrolyzing activity of HPU was measured by the alkaline nitroprussiate method [30] using ammonium sulfate as reference, to follow the purification of the holoenzyme. 


\subsection{Rat In Vivo Assays}

Twenty-four male 30 -day-old Wistar rats, housed at $22+3^{\circ} \mathrm{C}$ with a $12 / 12$-hour light/dark cycle, were used in the bioassays. Considering that $H$. pylori infection persists lifelong, we selected healthy young animals to simulate a chronic infection and to investigate HPU's neurotoxic effects in early life stages. Animals were separated in two groups $(n=4)$, and experiments were performed three times, in the same conditions. Control animals received sterile saline intraperitoneal (i.p.) injections. Treated animals received daily i.p. injections of $5 \mu \mathrm{g}$ HPU, for 7 days. Injections of $200 \mu \mathrm{L}$ were administered in the lower abdomen quadrant, intercalating left and right sides. On the $8^{\text {th }}$ day, animals were anesthetized with a ketamine $5 \%$, xylazine $2 \%$ solution and euthanized by decapitation, using a small rodent guillotine.

For the behavioral experiment, 30 male 30 -day-old Wistar rats, housed at $22+3^{\circ} \mathrm{C}$ with a 12/12-hour light/dark cycle, were used. Animals were separated into three groups $(n=10)$. Control animals received sterile saline intraperitoneal (i.p.) injections. Treated animals received daily i.p. injections of $5 \mu \mathrm{g}$ HPU or $1 \mathrm{mg} / \mathrm{kg}$ LPS, for 7 consecutive days. Injections of $100 \mu \mathrm{L}$ were administered in the lower abdomen quadrant, intercalating left and right sides. On the 8th day, animals were submitted to the behavioral tests described in 4.12. After the behavioral tests, animals were anesthetized with a ketamine $5 \%$, xylazine $2 \%$ solution and euthanized by decapitation, using a small rodent guillotine.

\subsection{Preparation of Brain Homogenates}

Rat brains were dissected, the hemispheres were separated and a medial fraction of brain tissue containing the hippocampus and the temporal lobe was collected. The tissues were homogenized in lysis buffer $(20 \mathrm{mM}$ Tris-HCl, $1 \mathrm{mM}$ EDTA, $1 \mathrm{mM}$ EGTA, $1 \mathrm{mM}$ PMSF, 1 mM Na3 $\mathrm{VO}_{4}$, protease inhibitor cocktail (Sigma, St. Louis, MO, USA) using a microtube pestle. Tissue homogenates were centrifuged at $12.000 \mathrm{~g}$, for 10 minutes, at $4^{\circ} \mathrm{C}$, and stored at $-80^{\circ} \mathrm{C}$.

\subsection{Western Blot Analysis}

Brain homogenates were denatured in sample buffer $(50 \mathrm{mM}$ Tris- $\mathrm{HCl}, \mathrm{pH} 6.8,1 \%$ SDS, 5\% 2- mercaptoethanol, 10\% glycerol, $0.001 \%$ bromophenol blue) and heated in a dry bath for $5 \mathrm{~min}$. Samples (20 $\mu \mathrm{g}$ total protein) were resolved in SDS-PAGE gels and proteins were transferred to $0.22 \mu \mathrm{m}$ nitrocellulose membranes (BioRad, Germany). Molecular mass markers (PageRuler, Thermo-Scientific) were run in parallel. Membranes were blocked with PBS-Tween (137 mM NaCl, $2.7 \mathrm{mM} \mathrm{KCl}, 10 \mathrm{mM} \mathrm{Na}_{2} \mathrm{HPO}_{4}, 1.8 \mathrm{mM} \mathrm{KH}_{2} \mathrm{PO}_{4}$, $0.1 \%$ Tween-20), containing 5\% bovine serum albumin (BSA; Sigma) and probed with the following antibodies: mouse anti-tau5 (Invitrogen, AHB0042, 1:1000), rabbit anti-ptau205 (Invitrogen, 44-738G, 1:1000), rabbit anti-ptau396 (Invitrogen, 710298, 1:1000), rabbit antiptau199 (Invitrogen, 701054, 1:1000), rabbit anti-Iba1 (Invitrogen, PA5-27436, 1:1000), rabbit anti-GSK-3beta (Sigma Aldrich, PK1111, 1:1000), rabbit anti-ure $\beta$ (Santa Cruz Biotech, sc-22742, 1:10,000), rabbit anti-Ure $\alpha$ (Santa Cruz Biotech, sc-21016, 1:10,000), rabbit antiactin (Sigma-Aldrich, A2066, 1:1000). Secondary antibodies (anti-mouse and anti-rabbit, 1:10,000) coupled to horseradish peroxidase were from Jackson ImmunoResearch Laboratories, Inc. (West Grove, PA, United States). The protein bands were visualized using a chemiluminescence detection kit (Millipore, Billerica, MA, United States). The levels of protein expression were quantified using the software ImageJ and normalized against $\beta$ actin as an endogenous control.

\subsection{Reactive Oxygen Species (ROS) Measurement}

In order to measure intracellular ROS production, carboxy-H2DCFDA (5-(-6)-carboxy2',7'-difluorodihydrofluorescein diacetate) was used following the protocols described in [59]. Cells (106 cells/well) were seeded in 96-well plates and incubated with the dye $(2 \mathrm{mM})$ for $30 \mathrm{~min}$ at $37^{\circ} \mathrm{C}$ in the dark, and then stimulated with 50,100 or $300 \mathrm{nM}$ $\mathrm{HPU}$ or $100 \mu \mathrm{M} \mathrm{H}_{2} \mathrm{O}_{2}$, and ROS production was measured 6 and 24 hours after treatment. 
Fluorescence $\left(\lambda_{\mathrm{ex}} 495 \mathrm{~nm} / \lambda_{\mathrm{em}} 527 \mathrm{~nm}\right)$ was measured using a Spectramax microplate reader (Molecular Devices, CA, USA). Experiments were performed in triplicates. The time dynamics in fluorescence was normalized against the control group df / F0 (\%), where F0 represents the fluorescence expressed by the control and df represents the change in fluorescence over time during the cell stimulus.

\subsection{Intracellular Calcium Measurement}

Calcium concentration was measured using the Fluo-4 dye (Invitrogen, F14201) following the protocol described in [59]. Cells (106 cells/well) were seeded in 96-well plates and incubated with the dye $(5 \mu \mathrm{M})$ for $45 \mathrm{~min}$ at $37{ }^{\circ} \mathrm{C}$ in the dark. Dye solution was removed, and cells were washed 3 times with $20 \mathrm{mM}$ phosphate buffer $\mathrm{pH} 7.5$, to remove excess dye. Cells were stimulated with 50, 100 or $300 \mathrm{nM} \mathrm{HPU}$ or $35 \mathrm{mM} \mathrm{KCl}$ and calcium concentration was measured 6 and 24 hours after treatment. Fluorescence $\left(\lambda_{\text {ex }} 488 \mathrm{~nm} / \lambda_{\mathrm{em}}\right.$ $530 \mathrm{~nm}$ ) was measured using a Spectramax microplate reader (Molecular Devices, CA, USA). Experiments were performed in triplicates. The time dynamics in fluorescence was normalized against the control group df / F0 (\%), where F0 represents the fluorescence expressed by the control and df represents the change in fluorescence over time during the cell stimulus.

\subsection{Cytokine Measurement}

BV-2 cells were cultured in 96 well plates and incubated with 10, 50, 100 or $300 \mathrm{nM}$ HPU. After 6 hours, supernatants were collected and stored at $-80{ }^{\circ} \mathrm{C}$. ELISA kits were used to detect the expression of IL-1 $\beta$ (88-7013-22) and TNF- $\alpha$ (88-7324-22) according to the manufacturer's instructions (Thermo Scientific, California, USA).

\subsection{Cell Viability}

The viability of BV-2 cells after HPU treatment was evaluated using the Thiazolyl Blue Tetrazolium Blue assay (MTT; M2128; Sigma-Aldrich), according to manufacturer's instructions. Cells were treated for $24 \mathrm{~h}$ with 10,50, 100 or $300 \mathrm{nM} \mathrm{HPU}$. After treatment, cells were incubated with MTT solution $(5 \mathrm{mg} / \mathrm{ml})$ for 4 hours at $37^{\circ} \mathrm{C}$. The solution was removed and $100 \mu \mathrm{L}$ DMSO was added to solubilize the precipitates. The plates were read at $570 \mathrm{~nm}$ in a M2 spectrophotometer (Molecular Devices, San Jose, CA, USA). The data is expressed as a percentage compared to control.

\subsection{Behavioral Tests}

\subsubsection{Object Recognition Task}

The method described by Ennaceur and Delacour, 1988 [85], was followed. An open field arena $(60 \times 40 \times 50 \mathrm{~cm})$ was placed in a dimly illuminated room. The objects to be discriminated were made of steel or glass and were carefully cleaned with $70 \%$ ethanol after each test to ensure the absence of olfactory cues. Exploration was defined as sniffing or touching the object with the nose and/or forepaws. The animals were habituated to the arena, exploring it for 4 consecutive days, 20 min per day, 6 days before the test. On the day before the test, the animals were placed in the open field arena with two identical objects (A and A) and explored for 5 min (training). On the day of the test, the animals were placed in the same apparatus for $5 \mathrm{~min}$ with a familiar and a novel object (A and B). In order to quantify object recognition memory, discrimination indexes (DI) were calculated as follows: time spent exploring the novel object subtracted the time spent exploring the familiar object, divided by the total exploration time spent exploring both objects (tnov - tfam) $/($ tnov + tfam)

\subsubsection{Elevated Plus Maze}

The method described in Furini et al., 2010 [86], was applied. Enhanced anxiety was evaluated using the elevated plus-maze test (EPM). The EPM is formed by two open arms and two closed arms of same size, united to a central square $\left(10 \mathrm{~cm}^{2}\right)$, elevated $45 \mathrm{~cm}$ from 
the floor. Two opposite arms had walls (10 cm high). Each arm was $40 \mathrm{~cm}$ long and $10 \mathrm{~cm}$ wide. The animals were placed in the center and had 5 minutes for free exploration. For measurement purposes, we counted the number of entries in each arm and time spent in open arms.

\subsection{Statistical Analysis}

All results are expressed as average \pm standard error of the mean (SEM) of at least three experiments, unless otherwise stated. The statistical significance of the differences between two groups was assessed using the unpaired Student's t-test and for multiple comparisons it was performed a one-way analysis of variance (ANOVA) followed by Tukey's post hoc test. Statistically significance was set at $p$-value $\leq 0.05$. GraphPad Prism 6 software (San Diego, CA, United States) was used to perform statistical analysis.

Author Contributions: Conceptualization, A.F.U., M.V.C.G., N.C-S., and C.R.C.; methodology, A.F.U., M.V.C.G., N.C-S., A.R.P., A.S-G., E.N., C.R.G.F.; validation, A.F.U., M.V.C.G., N.C-S., C.R.G.F.; formal analysis and data curation, A.F.U., M.V.C.G., C.R.G.F. and C.R.C.; writing - review and editing, A.F.U., M.V.C.G., N.C-S., C.R.G.F. and C.R.C.; supervision, C.R.C.; project administration, C.R.C..; funding acquisition, C.R.C.. All authors have read and agreed to the published version of the manuscript.

Funding: This work was financed by the Brazilian agencies: CAPES - Coordenação de Aperfeiçoamento de Pessoal de Nível Superior (Finance code 001 and Edital Toxinologia - grant 63/2010); CNPq - Conselho Nacional de Desenvolvimento Científico e Tecnológico (Edital Universal, grants 44.6052/2014-1 and 47.5908/2012-0), and FAPERGS (Fundação de Amparo a Pesquisa do Estado do Rio Grande do Sul; Ed. PPSUS, grant 17/2551-0001451-0); National Institute of Science and Technology in Brain Diseases, Excitotoxicity and Neuroprotection (CNPq 46.5671/1-2014 and FAPERGS 17/2551-0000516-3). A.F.U, M.V.C.G, and N.C-S. were recipients of CAPES graduate fellowships. C.R.C is a Productivity in Research Fellow of CNPq.

Institutional Review Board Statement: “The study was conducted according to the guidelines of the Declaration of Helsinki, in strict accordance with the Brazilian legislation (Law no. 6.638/1979) and approved by the Ethics Committees of Pontificia Universidade Católica do Rio Grande do Sul (protocols code 14/00414, Aug 24, 2015, and 10569, Aug 8, 2021) and Universidade Federal do Rio Grande do Sul (protocol 721.217, Nov 2014).

Acknowledgments: We acknowledge Adriele Scopel-Guerra, Federal University of Rio Grande do Sul, for helping in the in vivo approaches and production of HPU.

Conflicts of Interest: The authors declare no conflict of interest.

\section{References}

1. Doulberis, M.; Kotronis, G.; Thomann, R.; Polyzos, S.; Boziki, M.; Gialamprinou, D.; Deretzi, G.; Katsinelos, P.; Kountouras, J., Review: Impact of Helicobacter pylori on Alzheimer's disease: What do we know so far? Helicobacter 2018, 23, (1). 10.1111/hel.12454

2. Hooi, J. K. Y.; Lai, W. Y.; Ng, W. K.; Suen, M. M. Y.; Underwood, F. E.; Tanyingoh, D.; Malfertheiner, P.; Graham, D. Y.; Wong, V. W. S.; Wu, J. C. Y.; Chan, F. K. L.; Sung, J. J. Y.; Kaplan, G. G.; Ng, S. C., Global Prevalence of Helicobacter pylori Infection: Systematic Review and Meta-Analysis. Gastroenterology 2017, 153, (2), 420-429. 10.1053/j.gastro.2017.04.022

3. Wang, A. Y.; Peura, D. A., The prevalence and incidence of Helicobacter pylori-associated peptic ulcer disease and upper gastrointestinal bleeding throughout the world. Gastrointest Endosc Clin N Am 2011, 21, (4), 613-35. 10.1016/j.giec.2011.07.011

4. $\quad$ Ernst, P. B.; Gold, B. D., The disease spectrum of Helicobacter pylori: the immunopathogenesis of gastroduodenal ulcer and gastric cancer. Annu Rev Microbiol 2000, 54, 615-40. 10.1146/annurev.micro.54.1.615

5. Franceschi, F.; Covino, M.; Roubaud Baudron, C., Review: Helicobacter pylori and extragastric diseases. Helicobacter 2019, 24 Suppl 1, (S1), e12636. 10.1111/hel.12636 
6. Baj, J.; Forma, A.; Flieger, W.; Morawska, I.; Michalski, A.; Buszewicz, G.; Sitarz, E.; Portincasa, P.; Garruti, G.; Flieger, M.; Teresiński, G., Helicobacter pylori Infection and Extragastric Diseases-A Focus on the Central Nervous System. Cells 2021, 10, (9), 2191. 10.3390/cells10092191

7. Singh, R. K.; McMahon, A. D.; Patel, H.; Packard, C. J.; Rathbone, B. J.; Samani, N. J., Prospective analysis of the association of infection with CagA bearing strains of Helicobacter pylori and coronary heart disease. Heart 2002, 88, (1), 43-6. 10.1136/heart.88.1.43

8. Kountouras, J.; Zavos, C.; Katsinelos, P.; Vardaka, E., Glaucoma and Helicobacter pylori: eyes "wide open"! Dig Liver Dis 2012, 44, (11), 962-3; author reply 963. 10.1016/j.dld.2012.05.001

9. Grau, A. J.; Buggle, F.; Lichy, C.; Brandt, T.; Becher, H.; Rudi, J., Helicobacter pylori infection as an independent risk factor for cerebral ischemia of atherothrombotic origin. J Neurol Sci 2001, 186, (1-2), 1-5. 10.1016/s0022-510x(01)00507-x

10. Kunovsky, L.; Dite, P.; Jabandziev, P.; Dolina, J.; Vaculova, J.; Blaho, M.; Bojkova, M.; Dvorackova, J.; Uvirova, M.; Kala, Z.; Trna, J., Helicobacter pylori infection and other bacteria in pancreatic cancer and autoimmune pancreatitis. World journal of gastrointestinal oncology 2021, 13, (8), 835-844. 10.4251/wjgo.v13.i8.835

11. Kountouras, J.; Boziki, M.; Gavalas, E.; Zavos, C.; Deretzi, G.; Grigoriadis, N.; Tsolaki, M.; Chatzopoulos, D.; Katsinelos, P.; Tzilves, D.; Zabouri, A.; Michailidou, I., Increased Cerebrospinal Fluid Helicobacter pylori Antibody in Alzheimer's Disease. International Journal of Neuroscience 2009, 119, (6), 765-777. 10.1080/00207450902782083

12. Kountouras, J.; Tsolaki, M.; Gavalas, E.; Boziki, M.; Zavos, C.; Karatzoglou, P.; Chatzopoulos, D.; Venizelos, I., Relationship between Helicobacter pylori infection and Alzheimer disease. 2006, 66, (6), 938-940. 10.1212/01.wnl.0000203644.68059.5f

13. Kountouras, J.; Tsolaki, M.; Boziki, M.; Gavalas, E.; Zavos, C.; Stergiopoulos, C.; Kapetanakis, N.; Chatzopoulos, D.; Venizelos, I., Association between Helicobacter pylori infection and mild cognitive impairment. Eur J Neurol 2007, 14, (9), 97682. 10.1111/j.1468-1331.2007.01827.x

14. Lolekha, P.; Sriphanom, T.; Vilaichone, R.-K., Helicobacter pylori eradication improves motor fluctuations in advanced Parkinson's disease patients: A prospective cohort study (HP-PD trial). PLOS ONE 2021, 16, (5), e0251042. 10.1371/journal.pone.0251042

15. Zhong, R.; Chen, Q.; Zhang, X.; Li, M.; Lin, W., Helicobacter pylori infection is associated with a poor response to levodopa in patients with Parkinson's disease: a systematic review and meta-analysis. Journal of Neurology 2021. 10.1007/s00415-02110473-1

16. Roubaud Baudron, C.; Letenneur, L.; Langlais, A.; Buissonnière, A.; Mégraud, F.; Dartigues, J. F.; Salles, N.; Study, P. A. Q., Does Helicobacter pylori infection increase incidence of dementia? The Personnes Agées QUID Study. J Am Geriatr Soc 2013, 61, (1), 74-8. 10.1111/jgs.12065

17. Malaguarnera, M.; Bella, R.; Alagona, G.; Ferri, R.; Carnemolla, A.; Pennisi, G., Helicobacter pylori and Alzheimer's disease: a possible link. European Journal of Internal Medicine 2004, 15, (6), 381-386. 10.1016/j.ejim.2004.05.008

18. Wang, X. L.; Zeng, J.; Yang, Y.; Xiong, Y.; Zhang, Z. H.; Qiua, M.; Yan, X.; Sun, X. Y.; Tuo, Q. Z.; Liua, R.; Wang, J. Z., Helicobacter pylori Filtrate Induces Alzheimer-Like Tau Hyperphosphorylation by Activating Glycogen Synthase Kinase-3 beta. Journal of Alzheimers Disease 2015, 43, (1), 153-165. 10.3233/jad-140198

19. Marcus, E. A.; Scott, D. R., Cell lysis is responsible for the appearance of extracellular urease in Helicobacter pylori. Helicobacter 2001, 6, (2), 93-9. 10.1046/j.1523-5378.2001.00014.x

20. Marshall, B. J.; Barrett, L. J.; Prakash, C.; McCallum, R. W.; Guerrant, R. L., Urea protects Helicobacter (Campylobacter) pylori from the bactericidal effect of acid. Gastroenterology 1990, 99, (3), 697-702. 10.1016/0016-5085(90)90957-3

21. Montecucco, C.; Rappuoli, R., Living dangerously: how Helicobacter pylori survives in the human stomach. Nat Rev Mol Cell Biol 2001, 2, (6), 457-66. 10.1038/35073084 35073084 [pii] 
23. Tsuda, M.; Karita, M.; Morshed, M. G.; Okita, K.; Nakazawa, T., A urease-negative mutant of Helicobacter pylori constructed by allelic exchange mutagenesis lacks the ability to colonize the nude mouse stomach. Infect Immun 1994, 62, (8), 3586-9.

24. Khalilpour, A.; Kazemzadeh-Narbat, M.; Tamayol, A.; Oklu, R.; Khademhosseini, A., Biomarkers and diagnostic tools for detection of Helicobacter pylori. Appl Microbiol Biotechnol 2016, 100, (11), 4723-4734. 10.1007/s00253-016-7495-7

Eslaminejad, A.; Marashian, S. M.; Aboutorabi, M.; Sadr, M.; Agah, S., Determination of optimal time for reading of rapid urease test diagnosis of Helicobacter pylori. Gastroenterol Hepatol Bed Bench 2020, 13, (3), 232-237.

Carlini, C. R.; Ligabue-Braun, R., Ureases as multifunctional toxic proteins: A review. Toxicon 2016, 110, 90-109. 10.1016/j.toxicon.2015.11.020

Kappaun, K.; Piovesan, A. R.; Carlini, C. R.; Ligabue-Braun, R., Ureases: Historical aspects, catalytic, and non-catalytic properties - A review. J Adv Res 2018, 13, 3-17. 10.1016/j.jare.2018.05.010

Wassermann, G. E.; Olivera-Severo, D.; Uberti, A. F.; Carlini, C. R., Helicobacter pylori urease activates blood platelets through a lipoxygenase-mediated pathway. J Cell Mol Med 2010, 14, (7), 2025-34. 10.1111/j.1582-4934.2009.00901.x

Scopel-Guerra, A.; Olivera-Severo, D.; Staniscuaski, F.; Uberti, A. F.; Callai-Silva, N.; Jaeger, N.; Porto, B. N.; Carlini, C. R., The impact of Helicobacter pylori urease upon platelets and consequent contributions to inflammation. Front Microbiol 2017, 8, (Dec 12), 2447. https://doi.org/10.3389/fmicb.2017.02447

Uberti, A. F.; Olivera-Severo, D.; Wassermann, G. E.; Scopel-Guerra, A.; Moraes, J. A.; Barcellos-de-Souza, P.; Barja-Fidalgo, C.; Carlini, C. R., Pro-inflammatory properties and neutrophil activation by Helicobacter pylori urease. Toxicon 2013, 69, 240249. 10.1016/j.toxicon.2013.02.009

31. Iba, T.; Levy, J. H., Inflammation and thrombosis: roles of neutrophils, platelets and endothelial cells and their interactions in thrombus formation during sepsis. Journal of thrombosis and haemostasis : JTH 2018, 16, (2), 231-241. 10.1111/jth.13911

Olivera-Severo, D.; Uberti, A. F.; Marques, M. S.; Pinto, M. T.; Gomez-Lazaro, M.; Figueiredo, C.; Leite, M.; Carlini, C. R., A new role for Helicobacter pylori urease: Contributions to angiogenesis. Front Microbiol 2017, 8, e1883. 10.3389/fmicb.2017.01883 Wroblewski, L. E.; Shen, L.; Ogden, S.; Romero-Gallo, J.; Lapierre, L. A.; Israel, D. A.; Turner, J. R.; Peek, R. M., Jr., Helicobacter pylori dysregulation of gastric epithelial tight junctions by urease-mediated myosin II activation. Gastroenterology 2009, 136, (1), 236-46. 10.1053/j.gastro.2008.10.011

34. de Jesus Souza, M.; de Moraes, J. A.; Da Silva, V. N.; Helal-Neto, E.; Uberti, A. F.; Scopel-Guerra, A.; Olivera-Severo, D.; Carlini, C. R.; Barja-Fidalgo, C., Helicobacter pylori urease induces pro-inflammatory effects and differentiation of human endothelial cells: Cellular and molecular mechanism. Helicobacter 2019, 24, (3), e12573. 10.1111/hel.12573

Hanzel, C. E.; Iulita, M. F.; Eyjolfsdottir, H.; Hjorth, E.; Schultzberg, M.; Eriksdotter, M.; Cuello, A. C., Analysis of matrix metallo-proteases and the plasminogen system in mild cognitive impairment and Alzheimer's disease cerebrospinal fluid. J Alzheimers Dis 2014, 40, (3), 667-78. 10.3233/JAD-132282

36. Drake, C.; Boutin, H.; Jones, M. S.; Denes, A.; McColl, B. W.; Selvarajah, J. R.; Hulme, S.; Georgiou, R. F.; Hinz, R.; Gerhard, A.; Vail, A.; Prenant, C.; Julyan, P.; Maroy, R.; Brown, G.; Smigova, A.; Herholz, K.; Kassiou, M.; Crossman, D.; Francis, S.; Proctor, S. D.; Russell, J. C.; Hopkins, S. J.; Tyrrell, P. J.; Rothwell, N. J.; Allan, S. M., Brain inflammation is induced by comorbidities and risk factors for stroke. Brain Behav Immun 2011, 25, (6), 1113-22. 10.1016/j.bbi.2011.02.008

Barrientos, R. M.; Kitt, M. M.; Watkins, L. R.; Maier, S. F., Neuroinflammation in the normal aging hippocampus. Neuroscience 2015, 309, 84-99. 10.1016/j.neuroscience.2015.03.007

38. Olofsson, A.; Vallstrom, A.; Petzold, K.; Tegtmeyer, N.; Schleucher, J.; Carlsson, S.; Haas, R.; Backert, S.; Wai, S. N.; Grobner, G.; Arnqvist, A., Biochemical and functional characterization of Helicobacter pylori vesicles. Mol Microbiol 2010, 77, (6), 153955. 10.1111/j.1365-2958.2010.07307.x

39. Bruno, L.; Karagil, S.; Mahmood, A.; Elbediwy, A.; Stolinski, M.; Mackenzie, F. E., Mechanosensing and the Hippo Pathway in Microglia: A Potential Link to Alzheimer's Disease Pathogenesis? Cells 2021, 10, (11), 3144. 10.3390/cells10113144 
40. Mondragón-Rodríguez, S.; Perry G Fau - Luna-Muñoz, J.; Luna-Muñoz J Fau - Acevedo-Aquino, M. C.; Acevedo-Aquino Mc Fau - Williams, S.; Williams, S., Phosphorylation of tau protein at sites Ser(396-404) is one of the earliest events in Alzheimer's disease and Down syndrome. (1365-2990 (Electronic)).

41. Loeffler, D. A.; Smith, L. M.; Klaver, A. C.; Martić, S., Effects of antibodies to phosphorylated and non-phosphorylated tau on in vitro tau phosphorylation at Serine-199: Preliminary report. Exp Gerontol 2015, 67, 15-8. 10.1016/j.exger.2015.04.010

42. Avila, J.; Leon-Espinosa, G.; Garcia, E.; Garcia-Escudero, V.; Hernandez, F.; Defelipe, J., Tau Phosphorylation by GSK3 in Different Conditions. Int J Alzheimers Dis 2012, 2012, 578373. 10.1155/2012/578373

43. Schaffer, B. A.; Bertram, L.; Miller, B. L.; Mullin, K.; Weintraub, S.; Johnson, N.; Bigio, E. H.; Mesulam, M.; Wiedau-Pazos, M.; Jackson, G. R.; Cummings, J. L.; Cantor, R. M.; Levey, A. I.; Tanzi, R. E.; Geschwind, D. H., Association of GSK3B with Alzheimer disease and frontotemporal dementia. Arch Neurol 2008, 65, (10), 1368-74. 10.1001/archneur.65.10.1368

44. Hernandez, F.; Lucas, J. J.; Avila, J., GSK3 and tau: two convergence points in Alzheimer's disease. J Alzheimers Dis 2013, 33 Suppl 1, S141-4. 10.3233/JAD-2012-129025

45. Hanger, D. P.; Anderton, B. H.; Noble, W., Tau phosphorylation: the therapeutic challenge for neurodegenerative disease. Trends in molecular medicine 2009, 15, (3), 112-9. 10.1016/j.molmed.2009.01.003

46. Berlyne, D. E., Novelty and curiosity as determinants of exploratory behaviour. British Journal of Psychology. General Section 1950, 41, (1-2), 68-80. https://doi.org/10.1111/j.2044-8295.1950.tb00262.x

47. Rodgers, R. J.; Dalvi, A., Anxiety, defence and the elevated plus-maze. Neurosci Biobehav Rev 1997, 21, (6), 801-10. 10.1016/s0149-7634(96)00058-9

48. Lo, Y. C.; Shih, Y. T.; Wu, D. C.; Lee, Y. C., In vitro effects of Helicobacter pylori-induced infection in gastric epithelial AGS cells on microglia-mediated toxicity in neuroblastoma SH-SY5Y cells. Inflammation Research : official journal of the European Histamine Research Society ... [et al.] 2009, 58, (6), 329-35. 10.1007/s00011-009-8075-4

49. Alom-Ruiz, S. P.; Anilkumar, N.; Shah, A. M., Reactive oxygen species and endothelial activation. Antioxid Redox Signal 2008, 10, (6), 1089-100. 10.1089/ars.2007.2007

50. Frey, R. S.; Ushio-Fukai, M.; Malik, A. B., NADPH oxidase-dependent signaling in endothelial cells: role in physiology and pathophysiology. Antioxid Redox Signal 2009, 11, (4), 791-810. 10.1089/ars.2008.2220

51. Puri, B. K., Calcium Signaling and Gene Expression. In Adv Exp Med Biol, Springer International Publishing: 2020; pp 537545 .

Sattler, R.; Tymianski, M., Molecular mechanisms of calcium-dependent excitotoxicity. Journal of Molecular Medicine 2000, 78, (1), 3-13. 10.1007/s001090000077

53. Franklin, J. L.; Johnson, E. M., Block of neuronal apoptosis by a sustained increase of steady-state free Ca2+ concentration. Philos Trans R Soc Lond B Biol Sci 1994, 345, (1313), 251-6. 10.1098/rstb.1994.0102

54. Franklin, J. L.; Johnson, E. M., Suppression of programmed neuronal death by sustained elevation of cytoplasmic calcium. Trends Neurosci 1992, 15, (12), 501-8. 10.1016/0166-2236(92)90103-f

55. Medina, D. L.; Di Paola, S.; Peluso, I.; Armani, A.; De Stefani, D.; Venditti, R.; Montefusco, S.; Scotto-Rosato, A.; Prezioso, C.; Forrester, A.; Settembre, C.; Wang, W.; Gao, Q.; Xu, H.; Sandri, M.; Rizzuto, R.; De Matteis, M. A.; Ballabio, A., Lysosomal calcium signalling regulates autophagy through calcineurin and TFEB. Nat Cell Biol 2015, 17, (3), 288-99. 10.1038/ncb3114

56. Orrenius, S.; Zhivotovsky, B.; Nicotera, P., Regulation of cell death: the calcium-apoptosis link. Nat Rev Mol Cell Biol 2003, 4, (7), 552-65. 10.1038/nrm1150

57. Yang, M.; Wei, H., Anesthetic neurotoxicity: Apoptosis and autophagic cell death mediated by calcium dysregulation. Neurotoxicol Teratol 2017, 60, 59-62. 10.1016/j.ntt.2016.11.004

58. Bocchini, V.; Mazzolla, R.; Barluzzi, R.; Blasi, E.; Sick, P.; Kettenmann, H., An immortalized cell line expresses properties of activated microglial cells. J Neurosci Res 1992, 31, (4), 616-21. 10.1002/jnr.490310405 
59. Grahl, M. V. C.; Uberti, A. F.; Broll, V.; Bacaicoa-Caruso, P.; Meirelles, E. F.; Carlini, C. R., Proteus mirabilis Urease: Unsuspected Non-Enzymatic Properties Relevant to Pathogenicity. Int J Mol Sci 2021, 22, (13). 10.3390/ijms22137205

60. Boutajangout, A.; Wisniewski, T., The Innate Immune System in Alzheimer's Disease. International Journal of Cell Biology 2013, 2013, 1-7. 10.1155/2013/576383

61. Hunter, J. M.; Kwan, J.; Malek-Ahmadi, M.; Maarouf, C. L.; Kokjohn, T. A.; Belden, C.; Sabbagh, M. N.; Beach, T. G.; Roher, A. E., Morphological and pathological evolution of the brain microcirculation in aging and Alzheimer's disease. PLoS One 2012, 7, (5), e36893. 10.1371/journal.pone.0036893

62. Sheng, J. G.; Zhu, S. G.; Jones, R. A.; Griffin, W. S.; Mrak, R. E., Interleukin-1 promotes expression and phosphorylation of neurofilament and tau proteins in vivo. Exp Neurol 2000, 163, (2), 388-91. 10.1006/exnr.2000.7393

63. Koch, K. N.; Hartung, M. L.; Urban, S.; Kyburz, A.; Bahlmann, A. S.; Lind, J.; Backert, S.; Taube, C.; Muller, A., Helicobacter urease-induced activation of the TLR2/NLRP3/IL-18 axis protects against asthma. J Clin Invest 2015, 125, (8), 3297-302. 10.1172/JCI79337

64. Kacimi, R.; Giffard, R. G.; Yenari, M. A., Endotoxin-activated microglia injure brain derived endothelial cells via NF- $\kappa B$, JAK-STAT and JNK stress kinase pathways. Journal of Inflammation 2011, 8, (1), 7. 10.1186/1476-9255-8-7

65. Baik, S. C.; Kang, H. L.; Seo, J.-H.; Park, E. S.; Rhee, K.; Cho, M. J., Helicobacter pylori urease induces mouse death. J Bacteriol Virol 2005, 35, (3), 175-181.

66. Carlini, C. R.; Gomes, C.; Guimaraes, J. A.; Markus, R. P.; Sato, H.; Trolin, G., Central nervous effects of the convulsant protein canatoxin. Acta Pharmacol Toxicol (Copenh) 1984, 54, (3), 161-6.

67. Almeida, C. G. M.; Costa-Higuchi, K.; Piovesan, A. R.; Moro, C. F.; Venturin, G. T.; Greggio, S.; Costa-Ferro, Z. S.; Salamoni, S. D.; Peigneur, S.; Tytgat, J.; de Lima, M. E.; Silva, C. N. D.; Vinade, L.; Rowan, E. G.; DaCosta, J. C.; Dal Belo, C. A.; Carlini, C. R., Neurotoxic and convulsant effects induced by jack bean ureases on the mammalian nervous system. Toxicology 2021, 454, 152737. 10.1016/j.tox.2021.152737

68. Shaimardanova, A. A.; Solovyeva, V. V.; Chulpanova, D. S.; James, V.; Kitaeva, K. V.; Rizvanov, A. A., Extracellular vesicles in the diagnosis and treatment of central nervous system diseases. Neural Regen Res 2020, 15, (4), 586-596. 10.4103/16735374.266908

69. Turkina, M. V.; Olofsson, A.; Magnusson, K. E.; Arnqvist, A.; Vikstrom, E., Helicobacter pylori vesicles carrying CagA localize in the vicinity of cell-cell contacts and induce histone H1 binding to ATP in epithelial cells. FEMS Microbiol Lett 2015, 362, (11). 10.1093/femsle/fnv076

70. Adlimoghaddam, A.; Sabbir, M. G.; Albensi, B. C., Ammonia as a Potential Neurotoxic Factor in Alzheimer's Disease. Front Mol Neurosci 2016, 9, 57. 10.3389/fnmol.2016.00057

71. Skowronska, M.; Albrecht, J., Alterations of blood brain barrier function in hyperammonemia: an overview. Neurotox Res 2012, 21, (2), 236-44. 10.1007/s12640-011-9269-4

72. Skowrońska, M.; Zielińska, M.; Wójcik-Stanaszek, L.; Ruszkiewicz, J.; Milatovic, D.; Aschner, M.; Albrecht, J., Ammonia increases paracellular permeability of rat brain endothelial cells by a mechanism encompassing oxidative/nitrosative stress and activation of matrix metalloproteinases. J Neurochem 2012, 121, (1), 125-34. 10.1111/j.1471-4159.2012.07669.x

73. González-Domínguez, R.; García-Barrera, T.; Vitorica, J.; Gómez-Ariza, J. L., Metabolomic investigation of systemic manifestations associated with Alzheimer's disease in the APP/PS1 transgenic mouse model. Mol Biosyst 2015, 11, (9), 242940. $10.1039 / \mathrm{c} 4 \mathrm{mb} 00747 \mathrm{f}$

74. Ghazaleh, F. A.; Francischetti, I. M.; Gombarovits, M. E.; Carlini, C. R., Stimulation of calcium influx and platelet activation by canatoxin: methoxyverapamil inhibition and downregulation by cGMP. Arch Biochem Biophys 1997, 339, (2), 362-7. 10.1006/abbi.1997.9898 
75. Sawikr, Y.; Yarla, N. S.; Peluso, I.; Kamal, M. A.; Aliev, G.; Bishayee, A., Neuroinflammation in Alzheimer's Disease: The Preventive and Therapeutic Potential of Polyphenolic Nutraceuticals. Adv Protein Chem Struct Biol 2017, 108, 33-57. 10.1016/bs.apcsb.2017.02.001

76. Valcarcel-Ares, M. N.; Tucsek, Z.; Kiss, T.; Giles, C. B.; Tarantini, S.; Yabluchanskiy, A.; Balasubramanian, P.; Gautam, T.; Galvan, V.; Ballabh, P.; Richardson, A.; Freeman, W. M.; Wren, J. D.; Deak, F.; Ungvari, Z.; Csiszar, A., Obesity in Aging Exacerbates Neuroinflammation, Dysregulating Synaptic Function-Related Genes and Altering Eicosanoid Synthesis in the Mouse Hippocampus: Potential Role in Impaired Synaptic Plasticity and Cognitive Decline. J Gerontol A Biol Sci Med Sci 2019, 74, (3), 290-298. 10.1093/gerona/gly127

77. Ghosh, P.; Singh, R.; Ganeshpurkar, A.; Pokle, A. V.; Singh, R. B.; Singh, S. K.; Kumar, A., Cellular and molecular influencers of neuroinflammation in Alzheimer's disease: Recent concepts \& roles. Neurochem Int 2021, $151,105212$. 10.1016/j.neuint.2021.105212

78. Biringer, R. G., The Role of Eicosanoids in Alzheimer's Disease. Int J Environ Res Public Health 2019, 16, (14). 10.3390/ijerph16142560

79. Aisen, P. S.; Cummings, J.; Jack, C. R., Jr.; Morris, J. C.; Sperling, R.; Frolich, L.; Jones, R. W.; Dowsett, S. A.; Matthews, B. R.; Raskin, J.; Scheltens, P.; Dubois, B., On the path to 2025: understanding the Alzheimer's disease continuum. Alzheimers Res Ther 2017, 9, (1), 60. 10.1186/s13195-017-0283-5

80. Lee, Y. J.; Choi, D. Y.; Yun, Y. P.; Han, S. B.; Oh, K. W.; Hong, J. T., Epigallocatechin-3-gallate prevents systemic inflammation-induced memory deficiency and amyloidogenesis via its anti-neuroinflammatory properties. J Nutr Biochem 2013, 24, (1), 298-310. 10.1016/j.jnutbio.2012.06.011

81. Zakaria, R.; Wan Yaacob, W. M.; Othman, Z.; Long, I.; Ahmad, A. H.; Al-Rahbi, B., Lipopolysaccharide-induced memory impairment in rats: a model of Alzheimer's disease. Physiol Res 2017, 66, (4), 553-565. 10.33549/physiolres.933480

82. Zubareva, O. E.; Postnikova, T. Y.; Grifluk, A. V.; Schwarz, A. P.; Smolensky, I. V.; Karepanov, A. A.; Vasilev, D. S.; Veniaminova, E. A.; Rotov, A. Y.; Kalemenev, S. V.; Zaitsev, A. V., Exposure to bacterial lipopolysaccharidein early life affects the expression of ionotropic glutamate receptor genes and is accompanied by disturbances in long-term potentiation and cognitive functions in young rats. Brain Behav Immun 2020, 90, 3-15. 10.1016/j.bbi.2020.07.034

83. MacRae, M.; Macrina, T.; Khoury, A.; Migliore, M. M.; Kentner, A. C., Tracing the trajectory of behavioral impairments and oxidative stress in an animal model of neonatal inflammation. Neuroscience 2015, 298, 455-66. 10.1016/j.neuroscience.2015.04.048

84. Wang, X. L.; Zeng, J.; Feng, J.; Tian, Y. T.; Liu, Y. J.; Qiu, M.; Yan, X.; Yang, Y.; Xiong, Y.; Zhang, Z. H.; Wang, Q.; Wang, J. Z.; Liu, R., Helicobacter pylori filtrate impairs spatial learning and memory in rats and increases beta-amyloid by enhancing expression of presenilin-2. Front Aging Neurosci 2014, 6, 66. 10.3389/fnagi.2014.00066

85. Ennaceur, A.; Delacour, J., A new one-trial test for neurobiological studies of memory in rats. 1: Behavioral data. Behav Brain Res 1988, 31, (1), 47-59. 10.1016/0166-4328(88)90157-x

86. Furini, C. R.; Rossato, J. I.; Bitencourt, L. L.; Medina, J. H.; Izquierdo, I.; Cammarota, M., Beta-adrenergic receptors link $\mathrm{NO} / \mathrm{sGC} / \mathrm{PKG}$ signaling to BDNF expression during the consolidation of object recognition long-term memory. Hippocampus 2010, 20, (5), 672-83. 10.1002/hipo.20656 